\title{
Estrutura fundiária e concentração da propriedade da terra na colônia de imigrantes Dona Francisca (Joinville), Santa Catarina, 1850-1920
}

\author{
Luiz Mateus da Silva Ferreira ${ }^{1}$
}

\section{Resumo}

A partir de um conjunto variado de documentação primária, especialmente registros de proprietários de terras na colônia Dona Francisca e Joinville e o censo agrícola do Brasil de 1920, este artigo apresenta estatísticas e indicadores que permitem avaliar a estrutura fundiária e o grau de concentração da propriedade da terra na colônia Dona Francisca e Joinville no século XIX e Santa Catarina no início do século XX. As evidências apresentadas neste estudo demonstram que o tipo de colonização, o predomínio da pequena propriedade rural e a distribuição mais igualitária da terra em algumas regiões catarinenses, notadamente nas áreas de colonização europeia como Joinville, um dos maiores e mais importantes núcleos de imigração alemã do Brasil no século XIX, não impediram que Santa Catarina apresentasse índices de desigualdade fundiária semelhantes ou ainda mais elevados do que os de estados brasileiros marcados pela grande lavoura exportadora do açúcar e do café.

\section{Palavras-Chave}

Desigualdade fundiária. Colônia Dona Francisca. Joinville. Santa Catarina. Brasil.

\begin{abstract}
Based on records of landowners at Dona Francisca colony and the town of Joinville and in the Brazilian agricultural census of 1920, this article presents statistics and indicators that have allow the evaluation on concentration of land ownership at Dona Francisca colony and Joinville city in the nineteenth century, and in the state of Santa Catarina, Brazil, in the early twentieth century. The presented evidence in this investigation demonstrate that the model of colonization, the predominance of small rural properties, and the more equality on the distri-

- Artigo extraído da tese de doutorado "Terra, trabalho e indústria na colônia de imigrantes Dona Francisca (Joinville), Santa Catarina, 1850-1920", apresentada ao Programa de Pós-Graduação em História Econômica da Faculdade de Filosofia, Letras e Ciências Humanas da Universidade de São Paulo. O autor agradece os comentários e sugestões de Renato P. Colistete, Michel Deliberali Marson e Leonardo Weller.

1 Professor - Universidade Federal de Ouro Preto - Instituto de Ciências Sociais Aplicadas - Departamento de Economia - End.: Rua do Catete, 166 - Mariana/MG - Brasil - CEP: 35420-000. ORCiD: https://orcid.org/0000-0002-8177-5443.-E-mail:1uiz.ferreira@ufop.edu.br. Recebido: 16/08/2019. Aceite: 03/03/2020.

Editor Responsável: André Arruda Villela
\end{abstract}

(c) (i) (\$) Esta obra está licenciada com uma Licença Creative Commons Atribuição-Não Comercial 4.0 Internacional. 
bution of land in some regions of Santa Catarina, especially on areas of European colonization as Joinville, one of the largest and most important centers of German immigration in Brazil in the nineteenth century, didn't prevent that the state of Santa Catarina about presenting similar or even higher indexes of land inequality than those ones in Brazilian states marked by the great sugar and coffee exporting.

\section{Keywords}

Land Inequality. Dona Francisca colony. Joinville. Santa Catarina. Brazil.

\section{Classificação JEL}

N56. Q15. O15.

\section{Introdução}

Fundada em 1851, na região nordeste de Santa Catarina, a colônia Dona Francisca, hoje município de Joinville, foi concebida e organizada pela Kolonisations-Verein von 1849 in Hamburg (Sociedade Colonizadora de 1849 em Hamburgo), uma das maiores e mais importantes empresas estrangeiras de colonização a atuar no Brasil no século XIX. ${ }^{l}$ Vista pelo governo imperial brasileiro como "uma colônia destinada a servir de centro de atração de imigrantes", preferencialmente os de origem alemã, Dona Francisca recebeu mais de 17 mil colonos de língua alemã entre os anos 1851 e 1888, número equivalente a quase $20 \%$ do total de imigrantes alemães, suíços, austríacos, teuto-russos, noruegueses e dinamarqueses que desembarcaram no Brasil no período (Brasil 1859, 21; SCH 1891; Ferenczi; Willcox 1929; Ferreira 2019). Estabelecidos como pequenos proprietários, os colonos que chegaram à Dona Francisca eram, na sua absoluta maioria, agricultores, artífices e artesãos pobres que dependiam do crédito e do emprego oferecidos pela Sociedade Colonizadora de 1849 em Hamburgo (SCH) e particulares para pagar as dívidas contraídas com a compra das passagens, alimentos, ferramentas e utensílios, aquisição do terreno e construção de uma pequena e modesta moradia (Ferreira 2019).

1 A tradução literal do nome da empresa colonizadora (Kolonisations-Verein von 1849 in Hamburg) é Associação de Colonização de 1849 em Hamburgo. Entretanto, em vários documentos primários e na literatura em geral a tradução aparece como Sociedade Colonizadora de 1849 em Hamburgo. 
De outra parte, entre os colonos da Dona Francisca havia imigrantes relativamente abastados, pessoas com formação técnica e acadêmica, profissionais do setor urbano, pequenos comerciantes, acionistas e membros da SCH (Ficker 1965; Rodowicz 1992; Avé-Lallemant 1980; Schneider 1983; Ferreira 2019). Com recursos disponíveis para investir na colônia, alguns desses colonos relativamente abastados, visando adquirir ganhos futuros com a valorização e exploração econômica da terra, compraram mais de uma propriedade ou terrenos mais extensos que sua capacidade de cultivar. Também com o propósito de obter ganhos com a valorização futura das terras da Dona Francisca, alguns investidores estabelecidos na Europa adquiriram terrenos relativamente grandes na Dona Francisca. Em 1860, menos de 2\% do número de proprietários de terras na colônia possuíam mais de $40 \%$ da área total das propriedades particulares distribuídas na Dona Francisca. Foi essa realidade que fez os contemporâneos Robert AvéLallemant (1858), Luiz Pedreira do Coutto Ferraz (1859) e Johan Jakob von Tschudi (1861) advertirem sobre a tendência à concentração fundiária na Dona Francisca (Tschudi 1867, 361-362; Brasil 1859, 21; Avé-Lallemant 1980, 206-207).

Este artigo examina essa aparente tendência à concentração da propriedade da terra na colônia Dona Francisca (Joinville), um dos maiores e mais importantes núcleos de colonização europeia do Brasil no século XIX. Depois da análise da estrutura fundiária e da desigualdade na distribuição da propriedade da terra na Dona Francisca e Joinville, este artigo analisa a concentração fundiária no território de Santa Catarina em 1920. O objetivo desta análise é verificar se o predomínio da pequena propriedade rural e a distribuição mais igualitária da terra nas áreas de colonização europeia - como Joinville - resultou em menor concentração da propriedade da terra no estado catarinense como um todo. As principais fontes utilizadas neste estudo compreendem um conjunto variado de documentos primários: contratos de compra e venda de terrenos, títulos e listas de proprietários de terras, mapas e registros da direção da colônia Dona Francisca, livros de lançamentos de impostos territoriais de Joinville, relatórios da $\mathrm{SCH}$ e o recenseamento agrícola do Brasil de 1920. A partir das informações extraídas dessa documentação primária, são calculados indicadores que permitem avaliar a concentração fundiária na colônia Dona Francisca e Joinville no século XIX e nos municípios, regiões e estado de Santa Catarina em 1920. 
Os dados quantitativos e resultados apresentados neste estudo complementam a história econômica de Santa Catarina e do Brasil, uma vez que, apesar de relevantes no contexto da colonização brasileira no século XIX, Joinville e Santa Catarina ainda são pouco conhecidas na historiografia. Ao mesmo tempo, ao oferecer um conjunto de indicadores comparáveis entre regiões, este artigo amplia o escopo de análise a respeito da composição e distribuição da riqueza no Brasil no século XIX e início do século XX. ${ }^{2}$ Salienta-se que alguns estudos recentes têm produzido evidências sobre esse tema, porém, esses estudos concentram suas análises em regiões ou mercados exportadores, não sendo possível fazer uma avaliação adequada das diferenças e tendências da distribuição de riqueza e concentração fundiária entre regióes social e economicamente distintas, como Joinville e Santa Catarina, economias organizadas a partir do trabalho livre do colono europeu e da pequena produção mercantil voltada ao abastecimento interno e externo.

$\mathrm{O}$ artigo divide-se em sete seções incluindo esta introdução. $\mathrm{Na}$ segunda discute-se a questão fundiária na formação de Santa Catarina. A terceira seção analisa a distribuição da propriedade da terra na colônia Dona Francisca. Depois, nas quarta e quinta seções, avalia-se a concentração fundiária na Dona Francisca e Joinville no século XIX. A sexta seção examina a desigualdade entre proprietários de terras no município de Joinville e Santa Catarina em 1920. Por fim, apresentam-se as principais conclusões deste estudo.

\section{A questão fundiária na formação de Santa Catarina}

Existe uma tradição na historiografia brasileira que enfatiza como excepcional a formação socioeconômica do sul do Brasil em relação às demais regiões do país, sobretudo no que diz respeito à estrutura agrária e à organização social e do trabalho. ${ }^{3} \mathrm{Na}$ visão de Caio Prado Jr., o sistema de colonização do Rio Grande do Sul e Santa Catarina oferece particulari-

2 Por exemplo, ver: Colistete e Lamounier (2014); Marcondes (1998; 2011); Cardoso de Mello (1985); Garavazo (2006).

3 Nesse sentido ver: Prado Jr. (2006); Furtado, (2005); Carneiro (1950); Petrone, (1982); Waibel, (1958); Cardoso (1960; 2000). 
dades que, segundo o autor, distinguem-se nitidamente do conjunto da colonização brasileira. Nessas regiões, observou Prado Jr. $(2006,96)$

[...] A propriedade fundiária é muito subdividida, o trabalho escravo é raro, quase inexistente, a população é etnicamente homogênea [...]. Trata-se em suma de comunidades cujo paralelo encontramos apenas, na América, em suas regiões temperadas, e foge inteiramente às normas da colonização tropical formando uma ilha neste Brasil de grandes domínios escravocratas e seus derivados.

Para Prado Jr. (2006), o principal determinante do modelo inicial de colonização da região sul do Brasil foi a falta de condições naturais favoráveis à produção de gêneros tropicais de exportação. O latifúndio monocultor exportador escravista não teria se constituído como nas regiões do açúcar, predominando, no sul do país, o trabalho livre do colono europeu e a pequena propriedade agrícola. Em Santa Catarina, essa visão foi reiterada e reforçada nos estudos clássicos de Oswaldo Rodrigues Cabral (1970), Walter Fernando Piazza (1975; 1976; 1994; 1999) e Fernando Henrique Cardoso (1960; 2000).

Enfatizando a relação entre estrutura fundiária e escravidão, Oswaldo Rodrigues Cabral afirma que, no processo de formação econômica e social de Santa Catarina, não se encontram aqueles "domínios que se instalaram alhures e que deram origem àquela nobreza fundada no poder territorial" (Cabral 1970, 205). Ou ainda, na formação de Santa Catarina não se encontra nenhum domínio na "mesma categoria daqueles latifúndios cafeeiros e açucareiros existentes mais ao norte, nenhuma produção em larga escala, nenhum trabalho intensivo a exigir o maior emprego escravo [...]. Muito cedo iniciou-se então o regime da pequena propriedade e logo surgiu o trabalho livre" (Idem, Ibidem).

Para Walter Piazza, o predomínio da pequena propriedade fundiária na formação de Santa Catarina limitou o emprego da mão de obra escrava em larga escala no território catarinense. Nas palavras desse historiador: "a grande propriedade agrícola, que carecia de mão de obra mais numerosa e mais barata, era raríssima no litoral catarinense e só existente em maiores proporções no planalto, onde poucos homens, nas fainas do pastoreio, realizam a tarefa de apascentar grandes rebanhos" (Piazza 1975, 156). Mais 
tarde, o autor conclui sua análise dizendo: "na Capitania, depois província de Santa Catarina, a escravidão negra não teve as mesmas dimensões de outras partes do Brasil. Parcialmente tal [situação] se deve ao pequeno número de grandes propriedades agrícolas ou pastoris" (Ibidem 219).

Em publicação posterior, Walter Piazza sustenta que a utilização do trabalho escravo no território catarinense não se justificava economicamente, uma vez que Santa Catarina constituiu-se como região periférica, onde, segundo o autor, a ausência da grande lavoura voltada para a exportação e o predomínio da pequena unidade de produção familiar teriam restringido o investimento de capitais em mão de obra escrava. "Foi a existência da pequena propriedade, predominante, que mais acelerou o alijamento do braço escravo do cenário agrícola catarinense [...]”, assinalou Piazza $(1999,83)$.

Em outro trabalho, Walter Piazza buscou demonstrar o predomínio da pequena propriedade rural na formação da estrutura fundiária catarinense. Para tanto, o autor utilizou um grande volume de documentos oficiais e a partir deles concluiu que, primeiro, Blumenau "era, inquestionavelmente, uma colônia de pequenas propriedades agrícolas" (Piazza 1976, 655); segundo, a "distribuição que corresponde, hoje, à área urbana da cidade de Joinville, era povoada de pequenas, médias e grandes propriedades rurais" (Ibidem 661); terceiro, "o regime de concessão de terras aos casais açorianos demonstra [...] que não houve interesse em grandes concessões, e sim em pequenas glebas ocasionando, desde logo, a formação de minifúndios" no litoral catarinense (Ibidem 678).

Embora Piazza (1976) saliente que seu texto é um estudo introdutório, não se pode deixar de notar que o historiador não informa os critérios quantitativos e qualitativos utilizados para classificar pequena, média e grande propriedades rurais em Santa Catarina. O mesmo ocorre em Cabral (1970), Cardoso (1960; 2000) e em diversos estudos específicos do desenvolvimento econômico catarinense. Por exemplo, nas importantes contribuições de Mamigonian (1960; 1965; 1986), Cunha (1982; 1992), Hering (1987), Bossle (1988) e Seyferth (1999), faltam dados quantitativos e informações qualitativas para avaliar a estrutura fundiária dos principais núcleos de colonização europeia de Santa Catarina, que, segundo esses autores, desenvolveram-se a partir do regime de pequena propriedade agrícola. 
Desta forma, embora seja comumente reiterado na historiografia a predominância e importância da pequena propriedade rural na formação econômica e social catarinense, ainda não há estudos que forneçam dados quantitativos para avaliar adequadamente a estrutura fundiária de Santa Catarina durante o período de sua formação. Também pouco ou nada se pode afirmar sobre o grau de concentração da propriedade da terra no território catarinense no século XIX, nem mesmo nas principais áreas de colonização alemã de Santa Catarina (Joinville, Blumenau e Brusque), comumente destacadas por apresentarem uma organização econômica e social mais dinâmica e relativamente menos desigual, baseada na pequena propriedade e produção familiar. Nas próximas seções, apresentam-se evidências quantitativas que permitem avaliar em detalhes como era realmente a distribuição da propriedade da terra e a concentração fundiária na colônia Dona Francisca e Joinville no século XIX e Santa Catarina no início do século XX.

\section{Classificação e distribuição fundiária na colônia Dona Francisca}

Uma das principais dificuldades da análise da estrutura fundiária de qualquer região é a definição do conceito de pequena, média e grande propriedade. Essa dificuldade decorre do fato de espaços geográficos específicos possuírem características próprias (geografia, qualidade do solo, história, economia, organização social e do trabalho), o que dificulta transpor para outras áreas os aspectos e as categorias de determinados sistemas fundiários. Por exemplo, em artigo originalmente publicado em 1935, Caio Prado Júnior, baseado em características sociológicas típicas das fazendas paulistas, apresentou uma classificação fundiária para São Paulo. Pequenas propriedades foram definidas como aquelas que tinham até 25 alqueires; propriedades médias, entre 25 e 100 alqueires; e grandes propriedades, aquelas com mais de 100 alqueires (Prado Jr. 1945). Em hectares, a divisão seria correspondente a até 60,5 hectares para pequenas propriedades, de 60,5 a 242 hectares para médias e mais de 242 hectares para grandes propriedades. $^{4}$

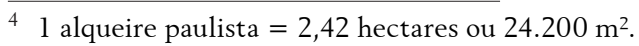


Leo Waibel, por sua vez, estudou as especificidades das propriedades coloniais do sul do Brasil. Analisando as características naturais (posição geográfica, qualidade do solo, clima e relevo), o tipo de colonização e o modelo de cultivo aplicado nas colônias do Brasil meridional, Waibel (1958) argumentou que 25 hectares de terras (cerca de 10 alqueires paulista) não eram suficientes para permitir a um agricultor do século XIX prover o sustento de sua família. Para o autor, a área mínima de um lote colonial no sul do país deveria ser de 55 a 65 hectares (22 a 27 alqueires paulista) em terras férteis e de 80 a 105 hectares (33 a 43 alqueires paulista) em terras ruins (Waibel 1958).

Já em seu estudo sobre a colonização alemã no Vale do Itajaí Mirim, região de Santa Catarina, Giralda Seyferth sustenta que uma propriedade rural contendo de 20 a 30 hectares não era suficiente ao sustento de uma família de colonos. A autora lembra que grande parte dos terrenos coloniais do Vale do Itajaí era formada por acidentes geográficos que restringiam a área cultivável do lote. Assim sendo, uma propriedade agrícola naquelas dimensões não permitia que o pousio das terras fosse muito longo, o que, segundo Seyferth (1999), acabava esgotando o solo mais rapidamente.

Em 1861, Johann Jakob von Tschudi já havia sustentado que, "no sistema agrícola brasileiro, no qual o solo é exaurido ininterruptamente", uma propriedade de 25 hectares era insuficiente para sustentar uma família (Tschudi 1867, 365). Observando as características do solo e o modo pelo qual se processava a limpeza dos terrenos na colônia Dona Francisca em 1852, o imigrante Otto Wachsmuth afirma que uma propriedade de 12,5 hectares de terras (cerca de 5 alqueires paulista) não era suficiente para uma família sobreviver (Wachsmuth apud Böbel; S. Thiago 2010). Também analisando as condições locais da Dona Francisca, o colono e cronista Theodor Rodowicz-Oswiecimsky estimava que, para uma família manter-se por conta própria na colônia, seriam necessários no mínimo 50 hectares de terras (Rodowicz 1992).

Com base nos estudos de Leo Waibel e Giralda Seyferth e nas observações dos contemporâneos citados acima, parece razoável aceitar que um terreno contendo 50 hectares era a menor porção de terra necessária ao sustento de uma família de colonos agricultores na Dona Francisca no século XIX. Portanto, uma propriedade de 50 hectares nessa colônia pode ser classificada como pequena, o que se aproxima da tipologia de Prado Jr. (1945), que definiu pequenas propriedades como aquelas que possuem 
até 25 alqueires ou 60,5 hectares. Como observaram Renato Colistete e Maria Lúcia Lamounier, a classificação de Caio Prado Jr. não é sem seus problemas, mas é uma base útil para descrever padrões de posse de terras e permite compará-los com diferentes regiões brasileiras, em particular com as zonas cafeeiras paulistas (Colistete; Lamounier 2014).

Assim, seguindo Prado Jr. (1945), assumem-se como pequenas as propriedades da colônia Dona Francisca com até 60,5 hectares; médias, as que têm entre 60,5 e 242 hectares; e grandes, as propriedades com mais de 242 hectares de terras. De acordo com essa classificação, a Tabela 1 mostra que nos anos 1852 e 1860 as pequenas propriedades correspondiam a 98,6\% dos terrenos distribuídos na Dona Francisca, enquanto as médias e grandes representavam 1,4\% das propriedades particulares da colônia. Em 1864, o número de pequenas propriedades representava 99,3\% do número de terrenos da Dona Francisca, contra menos de 1\% das médias e grandes propriedades.

Tabela 1 - Distribuição dos terrenos particulares na colônia Dona Francisca, 1852-1864

\begin{tabular}{lcccccc}
\hline \multirow{2}{*}{ Classificação } & \multicolumn{5}{c}{ Número de propriedades } \\
\cline { 2 - 7 } & 1852 & $\%$ & 1860 & $\%$ & 1864 & $\%$ \\
\hline Pequena & 145 & 98,6 & 992 & 98,6 & 1.356 & 99,3 \\
Média & 1 & 0,7 & 9 & 0,9 & 6 & 0,4 \\
Grande & 1 & 0,7 & 5 & 0,5 & 4 & 0,3 \\
\hline Total & 147 & 100 & 1.006 & 100 & 1.366 & 100 \\
\hline
\end{tabular}

Fontes: Calculado a partir dos registros de proprietários de terras na colônia Dona Francisca, cxs 1 a 4 , prat. 41. Série Sociedade Colonizadora. BR SCAHJ CF 12; Décimo e décimo terceiro relatórios da SCH, setembro de 1861 e outubro de 1864. Traduções Helena Remina Richlin. AHJ.

Na Tabela 2 a seguir percebe-se que, nos anos de 1852 e 1860, o tamanho médio das propriedades na colônia Dona Francisca foi muito superior à mediana, o que indica uma distribuição assimétrica à direita, isto é, o tamanho de algumas propriedades era muito maior que a grande maioria dos terrenos na colônia, elevando a área média. Também é possível observar essa discrepância pela grande diferença entre os valores das áreas mínimas e máximas das propriedades, que em 1852 variavam de $2.500 \mathrm{~m}^{2}$ (tamanho de $1,1 \%$ dos terrenos) a 500 hectares, área da propriedade do Príncipe de Joinville. 
Tabela 2 - Estatística descritiva dos terrenos particulares na colônia Dona Francisca, 1852-1864

\begin{tabular}{lccc}
\hline \multicolumn{1}{c}{ Indicadores } & 1852 & 1860 & 1864 \\
\hline Área média (hectares) & 11 & 13 & 12 \\
Área mediana (hectares) & 5 & 7 & 8 \\
Desvio padrão & 41,5 & 70 & 58 \\
Coeficiente de variação & 3,73 & 5,29 & 4,85 \\
Área mínima $\left(\mathrm{m}^{2}\right)$ & 2.500 & 875 & 250 \\
Área máxima (hectares) & 500 & 1.898 & 1.898 \\
Número total de propriedades & 147 & 1.006 & 1.366 \\
\hline
\end{tabular}

Fontes: Idem Tabela 1.

Nota-se na Tabela 2 que a diferença entre os valores das áreas mínimas e máximas das propriedades na colônia Dona Francisca em 1860 é ainda mais expressiva. $\mathrm{Na}$ época, coexistiam terrenos muito pequenos $-21 \%$ deles com menos de 1 hectare (o menor contendo $875 \mathrm{~m}^{2}$ ) - com propriedades muito grandes, a maior delas com 1.898 hectares, que pertencia ao Príncipe de Schönburg-Waldenburg. Além disso, o desvio padrão e o coeficiente de variação aumentam significativamente de 1852 para 1860. Tais medidas significam que houve maior variação no tamanho dos terrenos, cujas dimensões, em 1860, eram mais dispersas em relação à média. Em 1864, apesar do aumento da disparidade entre as áreas mínimas e máximas, houve redução na diferença entre a média e a mediana e uma leve queda no desvio padrão e coeficiente de variação (Tabela 2). Apesar desse declínio, os valores destas duas medidas de dispersão indicam a persistência de uma grande heterogeneidade na estrutura fundiária da colônia Dona Francisca.

A análise dos dados sugere que essa disparidade na distribuição da propriedade da terra na colônia Dona Francisca decorre da presença de outliers, casos excepcionais, isto é, investidores proprietários de grandes extensões de terras que não residiam na colônia, ou que residiam, mas não apresentavam características de um colono típico. No caso, as terras dos Príncipes de Joinville e de Schönburg-Waldenburg e as propriedades de Ernst Merck, Wilhelm Hühn, Arthur Guiguer, Georg W. Schröder e Bernard Poschaan, sócios ou membros da $\mathrm{SCH}$ que, visando a valorização futura das terras da colônia, adquiriram terrenos relativamente grandes na Dona Francisca. A Tabela 3 a seguir apresenta a estatística descritiva das propriedades particulares na colônia Dona Francisca excluindo esses outliers das distribuições. 
Tabela 3 - Estatística descritiva dos terrenos particulares na colônia Dona Francisca sem outliers, 1852-1864

\begin{tabular}{lccc}
\hline \multicolumn{1}{c}{ Indicadores } & 1852 & 1860 & 1864 \\
\hline Área média (hectares) & 7 & 9 & 9 \\
Área mediana (hectares) & 5 & 7 & 8 \\
Desvio padrão & 6,46 & 12,51 & 11,42 \\
Coeficiente de variação & 0,90 & 1,43 & 1,23 \\
Área mínima (m²) & 2.500 & 875 & 250 \\
Área máxima (hectares) & 37,5 & 291 & 291 \\
Número total de propriedades & 138 & 975 & 1.339 \\
\hline
\end{tabular}

Fontes: Idem Tabela 1.

Comparando os resultados das Tabelas 2 e 3, fica evidente o efeito dos outliers na distribuição da propriedade da terra na colônia Dona Francisca. Nota-se que, excluindo-se os outliers, o tamanho médio das propriedades declina nos três anos analisados, aproximando-se da mediana. Ainda mais significativa é a queda expressiva nos desvios padrão e coeficientes de variação das distribuições. Apesar disso, a questão fundamental na análise da distribuição da propriedade da terra é o grau de concentração fundiária, que será avaliado nas próximas seções.

\section{Concentração da propriedade da terra na colônia Dona Francisca}

A Tabela 4 a seguir oferece um conjunto de indicadores que permite uma análise mais precisa da desigualdade fundiária na colônia Dona Francisca. Foi calculada a proporção da área apropriada pelos estratos superiores, $1 \%, 5 \%$ e $20 \%$ dos proprietários da colônia, bem como os $50 \%$ e $20 \%$ da faixa inferior. Para sintetizar o grau de desigualdade na distribuição da propriedade da terra na Dona Francisca, foi estimado o coeficiente de concentração de Gini, que varia de 0 (perfeita igualdade) a 1 (desigualdade perfeita), de modo que, quanto mais próximo o coeficiente estiver de 1 , mais desigual é a distribuição. ${ }^{5}$

5 As estimativas dos indicadores e a metodologia de análise seguem Hoffmann (1979; 1998); Colistete e Lamounier (2014). 
Tabela 4 - Percentual de concentração fundiária e índice de Gini da distribuição da propriedade da terra na colônia Dona Francisca incluindo todos os proprietários, 1852-1864

\begin{tabular}{lccc}
\hline \multicolumn{1}{c}{ Área de terra apropriada } & 1852 & 1860 & 1864 \\
\hline $1 \%$ superior dos proprietários & 30,9 & 37,4 & 27,6 \\
$5 \%$ superiores dos proprietários & 46,7 & 49,6 & 37,3 \\
$20 \%$ superiores dos proprietários & 67,0 & 68,3 & 58,9 \\
$50 \%$ inferiores dos proprietários & 10,8 & 11,8 & 17,0 \\
$20 \%$ inferiores dos proprietários & 1,1 & 1,0 & 1,6 \\
Índice de Gini & 0,657 & 0,660 & 0,558 \\
\hline
\end{tabular}

Fontes: Idem Tabela 1.

Comparando as Tabelas 1 e 4, vê-se que o predomínio do número de pequenas propriedades $(98,6 \%)$ não resultou em menor concentração fundiária na colônia Dona Francisca nos anos 1852 e 1860. No primeiro ano, $1 \%$ dos proprietários concentrava 30,9\% da área total das propriedades particulares na colônia, enquanto os $50 \%$ da faixa inferior possuíam apenas $10,8 \%$ das terras. Ainda mais significativo é o fato de que os $5 \%$ dos proprietários do estrato superior concentravam mais de dois quintos da área total dos terrenos distribuídos na colônia até fins de 1852. Essa desigualdade é sintetizada pelo índice de Gini de 0,657. Em 1860, a concentração da propriedade da terra na Dona Francisca é ainda maior, com aumento da área apropriada pelos estratos superiores dos proprietários. Os 5\% dos proprietários concentravam, em 1860, quase a metade da área total das propriedades particulares na colônia. O Gini de 0,660 também reflete essa desigualdade.

A análise dos dados sugere que a desigualdade na apropriação da propriedade da terra na Dona Francisca resulta da disparidade entre os extremos da distribuição. Ou seja, essa discrepância parece ser resultado da distorção causada pela presença de outliers, no caso Arthur Guiguer, Wilhelm Hühn, Georg W. Schröder, Ernst Merck e os Príncipes de Joinville e de Schönburg-Waldenburg, que não residiam na colônia, e Bernhard Poschaan, estabelecido como importante proprietário de terras na Dona Francisca. Excluindo esses sete proprietários da análise, acha-se uma distribuição fundiária menos desigual nos três anos analisados, como mostra a Tabela 5 a seguir. 
Tabela 5 - Percentual de concentração fundiária e índice de Gini da distribuição da propriedade da terra na colônia Dona Francisca excluindo os outliers das distribuições, 1852-1864

\begin{tabular}{lccc}
\hline \multicolumn{1}{c}{ Área de terra apropriada } & 1852 & 1860 & 1864 \\
\hline $1 \%$ superior dos proprietários & 7,2 & 9,5 & 7,2 \\
$5 \%$ superiores dos proprietários & 21,5 & 24,2 & 19,2 \\
$20 \%$ superiores dos proprietários & 48,7 & 51,8 & 46,7 \\
$50 \%$ inferiores dos proprietários & 17,0 & 17,9 & 22,0 \\
$20 \%$ inferiores dos proprietários & 1,6 & 1,5 & 2,1 \\
Índice de Gini & 0,484 & 0,492 & 0,429 \\
\hline
\end{tabular}

Fontes: Idem Tabela 1.

Comparando as Tabelas 4 e 5, é significativo o declínio nos índices de Gini de 0,657 para 0,484 em 1852 , de 0,660 para 0,492 em 1860 , e de 0,558 para 0,429 em 1864, comprovando a distorção que os outliers provocavam na distribuição. A Tabela 6 abaixo sintetiza a variação nos índices de Gini estimados com e sem a presença de outliers.

Tabela 6 - Índice de Gini de concentração da propriedade da terra na colônia Dona Francisca com e sem outliers, 1852-1864

\begin{tabular}{ccc}
\hline \multirow{2}{*}{ Anos } & \multicolumn{2}{c}{ Índice de Gini } \\
\cline { 2 - 3 } & Gini com todos os proprietários & Gini sem outliers \\
\hline 1852 & 0,657 & 0,484 \\
1860 & 0.660 & 0.492 \\
1864 & 0,558 & 0,429 \\
\hline
\end{tabular}

Fontes: Tabelas 4 e 5.

Nota: o primeiro Gini inclui todos os proprietários de terras na colônia Dona Francisca, enquanto o segundo Gini apresenta o resultado excluindo os outliers das listas de proprietários de 1852, 1860 e 1864.

Voltando às Tabelas 4 e 5, observa-se que, em comparação aos anos anteriores, em 1864 houve uma queda significativa na proporção das terras apropriadas pelos estratos superiores e uma distribuição menos desigual entre todos os estratos, o que também é confirmado pelo coeficiente de Gini. Essa queda na desigualdade na apropriação da terra na colônia Dona Francisca é verificada com e sem a presença de outliers nas distribuições. Como houve aumento no número de terrenos e não ocorreram mudanças significativas no tamanho das áreas apropriadas pelos grandes proprietários, tudo indica que a redução do grau de desigualdade na distribuição 
da terra na colônia Dona Francisca é resultado do acréscimo do número de pequenas propriedades, o que elevou a área total abaixo da mediana da distribuição sem que houvesse alterações significativas no tamanho das terras apropriadas por indivíduo.

É importante deixar claro que os indicadores apresentados nas Tabelas 4 e 5 medem o grau de concentração da área total apropriada pelos proprietários de terras na Dona Francisca, ou seja, não são incluídos nas estimativas os não proprietários, que compreendem os colonos recém-chegados e ainda não estabelecidos. Também ficam de fora arrendatários, agregados, inquilinos e outras pessoas que viviam na colônia, mas não foram incluídos nos levantamentos da direção ou não constam como proprietários de terras nos registros da $\mathrm{SCH}$. Portanto, os indicadores acima devem ser entendidos como as estimativas mais baixas da concentração da terra, pois a inclusão dos não proprietários tenderia causar um aumento nos indicadores de desigualdade fundiária na colônia Dona Francisca, hoje município de Joinville.

\section{Concentração fundiária em Joinville no final do século XIX}

A Tabela 7 apresenta a distribuição de 1.502 propriedades urbanas e rurais do município de Joinville em 1891. O número de propriedades arroladas corresponde a quase $70 \%$ dos terrenos de Joinville naquele ano. Vê-se na Tabela 7 que 98\% das propriedades analisadas possuíam menos de 60,5 hectares (pequenas propriedades); 1,9\% tinham entre 60,5 e 242 hectares (propriedades médias); e $0,1 \%$ dos terrenos possuíam mais de 242 hectares (grandes propriedades). A Tabela 7 ainda mostra que as pequenas propriedades compreendiam $84,5 \%$ da área total dos imóveis arrolados, as propriedades médias abrangiam $8 \%$ da extensão territorial, e as grandes propriedades ocupavam $7,5 \%$ da área total dos imóveis analisados.

Tabela 7 - Distribuição das propriedades urbanas e rurais em Joinville, 1891

\begin{tabular}{ccccc}
\hline Extensão das propriedades & Número de propriedades & $\%$ & Área total em hectares & $\%$ \\
\hline Pequena & 1.472 & 98 & 24.783 & 84,5 \\
Média & 28 & 1,9 & 2.357 & 8,0 \\
Grande & 2 & 0,1 & 2.189 & 7,5 \\
\hline Totais & 1.502 & 100 & 29.330 & 100 \\
\hline
\end{tabular}

Fonte: "Livro de lançamento de receitas". Fundo Conselho Municipal, cx 5, prat. 549. AHJ. 
$\mathrm{Na}$ Tabela 8 nota-se que, excluindo os outliers das distribuições, em 1891 a área média das propriedades no município de Joinville e a diferença entre a média e a mediana aumentaram expressivamente em relação aos anos anteriores. Além disso, o desvio padrão e o coeficiente de variação indicam uma maior heterogeneidade fundiária em Joinville no ano de 1891. Entretanto, como veremos, a concentração da propriedade da terra no município joinvilense foi relativamente mais baixa em 1891 .

Tabela 8 - Estatística descritiva dos terrenos particulares na colônia Dona Francisca e Joinville excluindo os outliers das distribuições, 1852-1891

\begin{tabular}{lcccc}
\hline \multicolumn{1}{c}{ Indicadores } & 1852 & 1860 & 1864 & 1891 \\
\hline Área média (hectares) & 7 & 9 & 9 & 18 \\
Área mediana (hectares) & 5 & 7 & 8 & 14 \\
Desvio padrão & 6,46 & 12,51 & 11,42 & 15,42 \\
Coeficiente de variação & 0,90 & 1,43 & 1,23 & 0,85 \\
Área mínima (m $\left.{ }^{2}\right)$ & 2.500 & 875 & 250 & 250 \\
Área máxima (hectares) & 37,5 & 291 & 291 & 291 \\
Número total de propriedades & 138 & 975 & 1.339 & 1.474 \\
\hline
\end{tabular}

Fontes: Idem Tabelas 1 e 7.

No levantamento de 1891, o Príncipe de Joinville aparece como proprietário de vinte e sete imóveis em Joinville, cuja área total compreendia 895 hectares, e o Príncipe de Schönburg-Waldenburg possuía uma área contendo aproximadamente 1.900 hectares. A Tabela 9 a seguir mostra que, enquanto os $5 \%$ dos proprietários do estrato superior concentravam praticamente a mesma proporção de terras que os $50 \%$ da faixa inferior, $1 \%$ dos proprietários possuía $14,5 \%$ da área total dos terrenos arrolados. Excluindo-se as propriedades dos Príncipes de Joinville e de Schönburg da distribuição, percebe-se uma queda significativa na proporção da terra apropriada pelos $1 \%$ e $5 \%$ proprietários do estrato superior. Esses resultados indicam uma distribuição fundiária relativamente mais dispersa, mesmo considerando as terras dos Príncipes, o que é confirmado pelo índice de Gini de 0,438. Excluindo as propriedades dos Príncipes da análise, acha-se um Gini ainda menor, igual a 0,381 . 
Tabela 9 - Percentual de concentração fundiária e índice de Gini da distribuição da terra em Joinville com e sem outliers na distribuição, 1891

\begin{tabular}{lcc}
\hline \multicolumn{1}{c}{ Área de terra apropriada } & Com outliers & Sem outliers \\
\hline $1 \%$ superior dos proprietários & 14,5 & 6,1 \\
$5 \%$ superiores dos proprietários & 25,3 & 17,8 \\
$20 \%$ superiores dos proprietários & 48,6 & 43,3 \\
$50 \%$ inferiores dos proprietários & 22,0 & 24,3 \\
$20 \%$ inferiores dos proprietários & 4,5 & 5,0 \\
Índice de Gini & 0,438 & 0,381 \\
\hline
\end{tabular}

Fonte: "Livro de lançamento de receitas". Fundo Conselho Municipal, cx 5, prat. 549. AHJ.

Em resumo, analisando as distribuições sem a presença de outliers, observa-se uma queda expressiva na concentração fundiária na colônia Dona Francisca (Joinville), tendo o Gini declinado de 0,484 em 1852 para 0,381 em 1891. Como durante muito tempo a disponibilidade de terras demarcadas na colônia foi limitada, não acompanhando o aumento da sua população, que cresceu a uma taxa média anual de $12,7 \%$ entre os anos 1851 e 1886 (ver Tabela Al do Apêndice), tudo indica que a queda na desigualdade na distribuição da propriedade da terra na Dona Francisca foi resultado de três fatores principais. Em primeiro lugar, o fato de os colonos serem, na sua absoluta maioria, pobres e dependerem do crédito e do emprego oferecidos pela $\mathrm{SCH}$, associado às dificuldades financeiras da empresa colonizadora, limitou o financiamento para aquisição de lotes de terras maiores (Ferreira 2019). Em segundo lugar, o aumento da população da colônia combinado com a falta de terras demarcadas e disponíveis, provocou, devido aos efeitos naturais de mercado (oferta e demanda), uma alta nos preços dos terrenos na Dona Francisca. Nessas circunstâncias, a direção da colônia privilegiou a demarcação e venda de propriedades com área inferior a 20 hectares, que representaram mais de $85 \%$ dos terrenos comercializados na colônia Dona Francisca no período 1852-1891. ${ }^{6}$ Em terceiro lugar, dada a escassez de terrenos demarcados e disponíveis, houve parcelamento das médias e grandes propriedades particulares em terrenos menores, os quais eram vendidos a pequenos proprietários que prosperaram e aos colonos recém-chegados, ou distribuídos entre os membros da família,

6 Décimo e décimo terceiro relatórios da Sociedade Colonizadora de 1849 em Hamburgo, setembro de 1861 e outubro de 1864. Tradução Helena R. Richlin. AHJ; "Registro de lote de terra", cxs 1 a 4, prat. 41; "Livro caixa", cxs 1 e 2, prat. 40. Série Sociedade Colonizadora. BR SCAHJ CF 12. "Livro de lançamento de receitas". Fundo Conselho Municipal, cx 5, prat. 549. AHJ. 
geralmente numerosa (Ferreira 2019). Como resultado, houve acréscimo do número de pequenas propriedades, o que elevou a área total abaixo da mediana da distribuição e à redução da disparidade entre a proporção das terras apropriadas pelos estratos superiores e inferiores dos proprietários de terras na colônia Dona Francisca (Joinville).

Na próxima seção, consideraremos os dados do censo agrícola do Brasil de 1920, a fim de verificar a persistência ou não da queda no grau de concentração fundiária entre proprietários de terras no município de Joinville. A análise será feita no contexto do estado de Santa Catarina, com o que será possível avaliar se as características da propriedade da terra em Joinville eram similares ou divergentes do que se consolidou no conjunto do estado catarinense no início do século XX.

\section{Concentração fundiária em Joinville e Santa Catarina em 1920}

O censo agrícola do Brasil de 1920 abrangeu 37,6\% do território catarinense, sendo apuradas informações de 33.744 imóveis rurais. No município de Joinville, foram recenseadas 2.608 propriedades, que somadas compreendiam 73.534 hectares, número duas vezes e meia maior que a área total das 1.502 propriedades particulares arroladas no levantamento de 1891. A Tabela 10 apresenta a distribuição das propriedades rurais recenseadas no município de Joinville em 1920.

Tabela 10 - Distribuição das propriedades rurais em Joinville, 1920

\begin{tabular}{lcccc}
\hline Extensão das propriedades & Número de propriedades & $\%$ & Área total em hectares & $\%$ \\
\hline Menos de 41 hectares & 2.333 & 89,5 & 48.993 & 66,6 \\
$41-100$ hectares & 237 & 9,1 & 13.746 & 18,7 \\
$101-200$ hectares & 27 & 1,0 & 3.942 & 5,4 \\
$201-400$ hectares & 7 & 0,3 & 1.827 & 2,5 \\
$401-1000$ hectares & 2 & 0,1 & 1.252 & 1,7 \\
$1001-2000$ hectares & 2 & 0,1 & 3.774 & 5,1 \\
$2001-5000$ hectares & - & - & - & - \\
$5001-10000$ hectares & - & - & - & - \\
$10001-25000$ hectares & - & - & - & - \\
25001 e mais hectares & - & - & - & - \\
\hline Total & 2.608 & 100 & 73.534 & 100 \\
\hline
\end{tabular}

Fonte: Brasil (1923, 190-192). 
Como o censo de 1920 apresenta as informações dos proprietários de terras por estratos e oferece uma definição de pequena, média e grande propriedade diferente da proposta neste estudo para analisar a distribuição da propriedade da terra na colônia Dona Francisca e Joinville no século XIX, não é possível comparar os coeficientes de Gini estimados para os anos analisados anteriormente sem antes organizar os dados de acordo com a classificação do recenseamento de 1920. Feita essa organização, é possível estimar o Gini por estrato para os anos 1852, 1860, 1864 e 1891 e compará -los com o resultado da estimação feita com base nos dados censitários de 1920. A Figura 1 mostra os índices de Gini de concentração da área total apropriada pelos proprietários de terras de Joinville, excluindo os outliers observados nas distribuições.

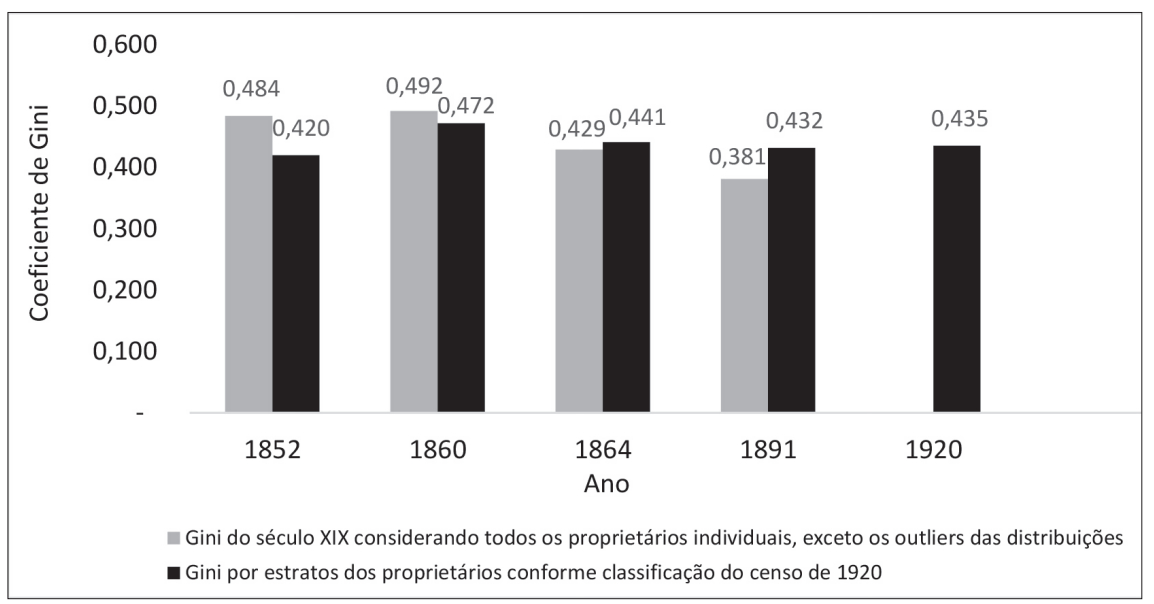

Figura 1 - Índice de Gini de concentração da propriedade da terra por estratos de proprietários em Joinville no período 1852-1920, conforme a classificação do censo agrícola de 1920

Fontes: Idem Tabelas 1, 7 e 10.

Comparando os Ginis calculados para os anos do século XIX (incluindo todos os proprietários individuais da colônia Dona Francisca e Joinville, exceto os outliers das distribuições) com os Ginis calculados por estratos de acordo com o recenseamento agrícola de 1920, percebe-se que os Ginis de 1860 e 1864 variam levemente, enquanto os índices de 1852 e 1891 variam mais fortemente. Essas variações decorrem das diferenças de classificação dos dados de todos os proprietários de terras (como na análise dos anos do 
século XIX) e dos proprietários por estratos (como o recenseamento de 1920), sendo a desigualdade dentro dos estratos a principal causa das diferenças. Por exemplo, conforme o censo de 1920, o primeiro estrato inclui todos os proprietários que possuem até 41 hectares de terras. Nesse grupo, há proprietários de terrenos com 1 hectare ou menos e de 10, 20, 30 e 40 hectares. Devido a essas disparidades, os índices de Gini estimados inicialmente, isto é, considerando o conjunto dos proprietários individuais excluindo os outliers das distribuições (Tabelas 5 e 9), refletem melhor a desigualdade na apropriação da terra na colônia Dona Francisca e Joinville no século XIX. Não obstante, as estimativas do Gini por estratos apresentadas na Figura 1 são interessantes para visualizar um padrão no grau de concentração fundiária em Joinville, com Gini sempre em torno de 0,45.

Analisando o conjunto das propriedades rurais recenseadas em Santa Catarina no ano de 1920, percebe-se que os estabelecimentos agrícolas com menos de 101 hectares (pequenas propriedades, segundo o censo de 1920) representavam $87,3 \%$ dos imóveis rurais do estado catarinense naquele ano. Apesar desse predomínio do número de pequenas propriedades, a área total ocupada por esses imóveis rurais compreendia $25,1 \%$ da superfície agrícola recenseada, como se pode constatar na Tabela 11.

Tabela 11 - Distribuição das propriedades rurais em Santa Catarina, 1920

\begin{tabular}{lcccc}
\hline Extensão das propriedades & Número de propriedades & $\%$ & Área total em hectares & $\%$ \\
\hline Menos de 41 hectares & 22.730 & 67,4 & 470.351 & 13,1 \\
$41-100$ hectares & 6.744 & 20,0 & 430.818 & 12,0 \\
$101-200$ hectares & 1.879 & 5,6 & 276.272 & 7,7 \\
$201-400$ hectares & 1.073 & 3,2 & 307.906 & 8,6 \\
$401-1000$ hectares & 804 & 2,4 & 523.041 & 14,6 \\
$1001-2000$ hectares & 300 & 0,9 & 443.770 & 12,4 \\
$2001-5000$ hectares & 166 & 0,5 & 488.832 & 13,6 \\
$5001-10000$ hectares & 32 & 0,1 & 220.139 & 6,1 \\
$10001-25000$ hectares & 12 & 0,04 & 168.951 & 4,7 \\
25001 e mais hectares & 4 & 0,01 & 255.160 & 7,1 \\
\hline Total & 33.744 & 100 & 3.585 .240 & 100 \\
\hline
\end{tabular}

Fonte: Brasil (1923, 190-192). 
A Tabela 11 ainda permite constatar que, embora as propriedades com área superior a 10 mil hectares correspondessem, em 1920, a 0,05\% dos imóveis rurais catarinenses, sua extensão territorial representava quase a metade da área ocupada pelos terrenos com menos de 101 hectares (pequenas propriedades). Essa disparidade na distribuição da terra sugere que, em 1920, o predomínio do número absoluto de pequenas propriedades não se traduziu em menor concentração fundiária em Santa Catarina. Tal fato é confirmado pelo índice de Gini de 0,766 para o conjunto do estado catarinense. Este resultado é igual ao Gini de concentração fundiária entre proprietários de terras em São Paulo e superior aos do Maranhão $(0,742)$, Minas Gerais $(0,726)$ e Pernambuco $(0,627)$ no ano de 1920 , algo surpreendente dado o passado colonial dessas regiões - ver Tabela A2 do Apêndice.

A Tabela 12 a seguir apresenta o Gini de concentração da propriedade da terra dos municípios e regiões catarinenses em 1920. A distribuição mais igualitária em algumas localidades, notadamente Brusque $(0,364)$, Urussanga $(0,383)$, Joinville $(0,435)$, Nova Trento $(0,447)$, Blumenau $(0,434)$ e Cruzeiro $(0,412)$ - atual Joaçaba -, não foi suficiente para definir uma estrutura fundiária menos concentrada no estado de Santa Catarina em 1920, conforme demonstrou o índice de Gini, igual a 0,766. É importante deixar claro que esse resultado mede o grau de concentração da área total apropriada pelos proprietários de terras, ou seja, não são incluídos na estimativa os não proprietários, arrendatários, agregados e inquilinos. 
Tabela 12 - Concentração da área apropriada por proprietários de terras em Santa Catarina, regiões e municípios catarinenses, 1920

\begin{tabular}{ll|ll}
\hline \multicolumn{1}{c}{ Regiões e Municípios } & Gini & \multicolumn{1}{c}{ Regiões e Municípios } & Gini \\
\hline Grande Florianópolis & 0,812 & Norte Catarinense & 0,755 \\
Florianópolis & 0,712 & Joinville & 0,435 \\
Palhoça & 0,858 & Porto União & 0,855 \\
São José & 0,644 & São Francisco do Sul & 0,570 \\
Biguaçu & 0,555 & Mafra & 0,764 \\
Tijucas & 0,625 & São Bento do Sul & 0,652 \\
Nova Trento & 0,447 & Campo Alegre & 0,625 \\
Oeste Catarinense & 0,790 & Canoinhas & 0,634 \\
Chapecó & 0,818 & Itaiópolis & 0,661 \\
Cruzeiro & 0,412 & Parati & 0,549 \\
Vale do Itajaí & 0,505 & Sul Catarinense & 0,572 \\
Blumenau & 0,434 & Araranguá & 0,572 \\
Brusque & 0,364 & Garopaba & 0,546 \\
Camboriú & 0,490 & Imaruí & 0,460 \\
Porto Belo & 0,580 & Jaguaruna & 0,517 \\
Itajaí & 0,670 & Laguna & 0,643 \\
Serrana & 0,685 & Orleans & 0,544 \\
Campos Novos & 0,726 & Tubarão & 0,542 \\
Lages & 0,671 & Urussanga & 0,383 \\
Curitibanos & 0,663 & & \\
São Joaquim & 0,594 & & \\
\hline Santa Catarina & & & \\
\hline & & & \\
\hline
\end{tabular}

Fonte: Calculado de Brasil (1923, 190-192).

Vale notar, os Ginis municipais apresentados na Tabela 12 são negativa e moderadamente correlacionados com o fato de os municípios terem sido ou não núcleos de colonização europeia no século XIX - a correlação de Pearson é igual a menos 0,61 . Ainda que a correlação de $61 \%$ seja moderada, o sinal negativo apresenta a relação esperada, isto é, quanto maior o número de localidades cuja formação baseada na pequena propriedade foi preservada, menor a concentração fundiária. 
Assim, uma hipótese para o elevado grau de concentração fundiária no estado catarinense em 1920 é o fato de que, em 1916, uma área considerável que estava em litígio entre Santa Catarina e Paraná foi incorporada ao território catarinense. Essa área incluía os municípios de Canoinhas, Porto União, Campos Novos, Curitibanos, Chapecó, Cruzeiro e partes de Campo Alegre, São Bento do Sul e Mafra. A Figura 2 mostra o território de litígio que deu origem à Guerra do Contestado (1912-1916). ${ }^{7}$

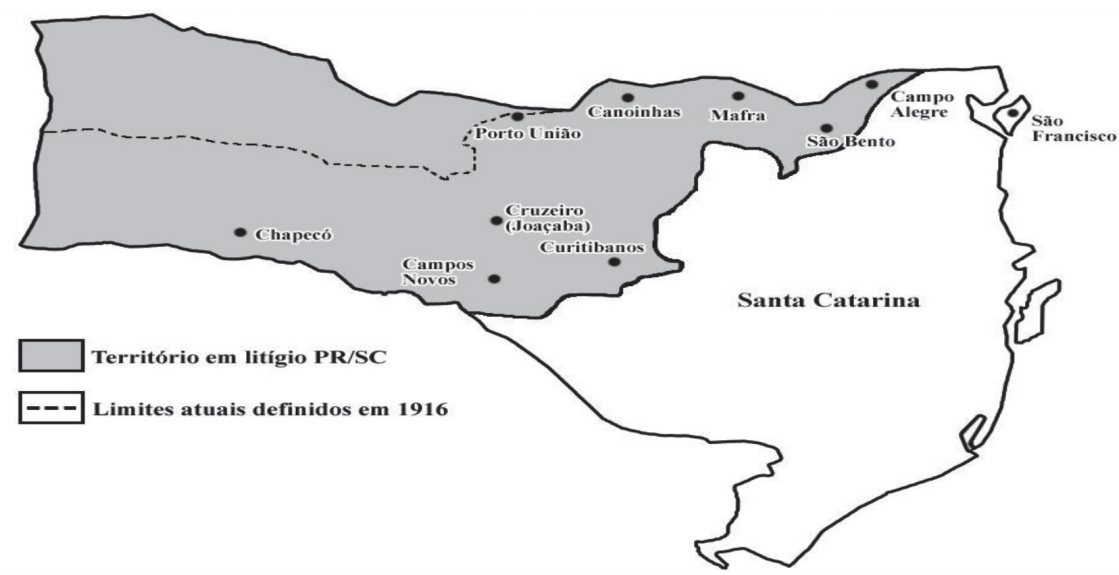

Figura 2 - Território em litígio entre Paraná e Santa Catarina no início do século XX Fonte: Editado pelo autor com base em Santa Catarina (1958).

Como exercício contrafactual, excluíram-se os municípios de São Bento do Sul, Canoinhas, Mafra, Porto União, Campos Novos, Chapecó, Cruzeiro, Campo Alegre e Curitibanos da análise e estimou-se a concentração da propriedade da terra em Santa Catarina novamente. Como resultado, achou-se um Gini ligeiramente menor $(0,740)$ e uma correlação negativa e moderada $(-0,64)$ entre os índices de concentração municipais de 1920 e as áreas de colonização europeia do século XIX em Santa Catarina. Esse resultado mostra que o tipo de colonização, o predomínio da pequena propriedade rural e a distribuição mais igualitária da terra em algumas regiões catarinenses, especialmente nas áreas de colonização europeia como Joinville, Vale do Itajaí e partes do sul de Santa Catarina não produziram uma estrutura fundiária menos concentrada no conjunto estado catarinense no início do século XX.

7 Sobre a Guerra do Contestado ver Serpa (1999); Auras (2001); Machado (2004). 


\section{Conclusões}

As evidências apresentadas neste artigo demonstram que, apesar do predomínio da pequena propriedade na colônia Dona Francisca, a concentração da propriedade da terra na colônia mostrou-se bastante elevada inicialmente, conforme demonstraram os índices Ginis de 0,657 em 1852 e de 0,660 em 1860. Esses resultados parecem confirmar as observações de Robert Avé-Lallemant (1858), Luiz Pedreira do Coutto Ferraz (1859) e Johann Jakob von Tschudi (1861), contemporâneos que, depois de visitarem a colônia, denunciaram uma certa tendência à concentração fundiária na Dona Francisca. Contudo, a análise dos registros de proprietários de terras na colônia revelou que essa aparente tendência à concentração fundiária decorria da presença de outliers nas distribuições, isto é, poucos e excepcionalmente grandes proprietários, como os Príncipes de Joinville e de Schönburg-Waldenburg e investidores que não residiam na colônia, ou que residiam, mas não apresentavam características de um colono típico. Excluindo-se esses outliers da análise, verificou-se uma distribuição mais dispersa e menos desigual entre os colonos da Dona Francisca. Para o ano de 1852, achou-se um Gini de concentração da propriedade da terra igual a 0,484 e, para 1860 o Gini foi de 0,492.

A análise dos registros de 1864, excluindo os outliers da distribuição, revelou uma queda expressiva na concentração da propriedade da terra na Dona Francisca, tendo o Gini declinado de 0,492 em 1860 para 0,429 em 1864. Mantendo essa tendência de queda na concentração da propriedade fundiária em Joinville, o Gini foi igual a 0,381 em 1891. Tudo indica que essa queda na concentração da terra na Dona Francisca e no município de Joinville foi resultado de três fatores principais. O primeiro foi o fato de que a entrada contínua de imigrantes associada à falta de terras disponíveis levou a direção da colônia a privilegiar a demarcação de lotes de terras menores. O segundo fator está associado às dificuldades financeiras da $\mathrm{SCH}$, que devido à escassez de recursos e a dívida crescentes dos colonos limitou o financiamento para aquisição de terrenos maiores. O terceiro fator que contribuiu para a queda no índice de desigualdade fundiária na Dona Francisca foi a escassez de terrenos demarcados e disponíveis, o que levou ao parcelamento das médias e grandes propriedades particulares em lotes de terras menores, os quais eram vendidos a colonos estabelecidos e, principalmente, a imigrantes recém-chegados ou divididos entre os membros da família. Por consequência, houve acréscimo do número de pequenas propriedades na Dona Francisca, o que elevou a área total abaixo da 
mediana da distribuição e redução do grau de concentração da propriedade da terra na colônia.

Em 1920, o predomínio da pequena propriedade rural no município de Joinville determinou uma desigualdade na distribuição da propriedade da terra relativamente baixa, com Gini igual a 0,435. O mesmo, porém, não ocorreu no estado de Santa Catarina como um todo, onde, apesar do grande número de pequenos proprietários $(87,3 \%)$, a concentração da propriedade da terra mostrou-se bastante elevada em 1920, como demonstrou o índice de Gini $(0,766)$. Ou seja, a distribuição da terra menos desigual resultante da colonização em Joinville e outras regiões catarinenses de colonização europeia não impediu que o estado de Santa Catarina apresentasse no início do século XX índices de desigualdade fundiária semelhantes, ou ainda mais elevados, do que os de estados marcados pela grande lavoura exportadora do açúcar e do café.

\section{Referências}

\section{Publicações Oficiais}

Brasil. Ministerio do Império. Relatorio de Luiz Pedreira do Coutto Ferraz apresentado ao Ministro e Secretario de Estado dos Negocios do Imperio Sergio Teixeira de Macedo. Rio de Janeiro: Typographia Universal de Laemmert, 1859.

Brasil. Ministerio da Agricultura. Directoria Geral de Estatistica. Recenseamento do Brazil, Realizado em 1 de setembro de 1920. Agricultura. Vol. III, $1^{\text {a }}$ parte. Rio de Janeiro: Typographia da Estatistica, 1923.

Santa Catarina. Departamento Estadual de Geografia e Cartografia, Atlas de Santa Catarina. Florianópolis: DEGC/SC, 1958.

\section{Documentos de Acervos}

Arquivo Histórico de Joinville (AHJ)

Acervo Domínio Dona Francisca, diversos documentos.

Acervo Fundo Conselho Municipal, "Livro de lançamento de receitas".

Coleção Carlos Ficker, diversos documentos.

Sociedade Colonizadora de Hamburgo (SCH), "Relatórios da Direção da Sociedade Colonizadora de 1849 em Hamburgo", de 1851 a 1892. Traduções Helena Remina Richlin. AHJ. 


\section{Referências Bibliográficas}

Avé-Lallemant, Robert. 1980. Viagens pelas províncias de Santa Catarina, Paraná e São Paulo (1858). Tradução Teodoro Cabral. Belo Horizonte: Editora Itatiaia; São Paulo: Editora da USP.

Auras, Marli. 2001. "Guerra do Contestado: a organização da irmandade cabocla". Florianópolis: EDUFSC.

Böbel, Maria Thereza; S. Thiago, Raquel. 2010. “Joinville: os pioneiros”. Vol. 1. Joinville: UNIVILLE.

Bossle, Ondina Pereira. 1988. "História da industrialização catarinense: das origens à integração no desenvolvimento brasileiro". Florianópolis: CNI/FIESC.

Cabral, Oswaldo R. 1970. "História de Santa Catarina". Rio de Janeiro: Editora Laudes.

Cardoso, F. Henrique; Ianni, Octavio. 1960. "Cor e mobilidade social em Florianópolis: aspectos das relações entre negros e brancos numa comunidade do Brasil meridional". São Paulo: Cia Nacional.

Cardoso, F. Henrique. 2000. "Negros em Florianópolis: relações sociais e econômicas". Florianópolis: Insular. Cardoso de Mello, Zélia M. 1985. "Metamorfoses da riqueza: São Paulo, 1845-1895”. São Paulo: Hucitec.

Carneiro, J. Fernando. 1950. "Imigração e colonização no Brasil". Rio de Janeiro: Universidade do Brasil.

Colistete, Renato P.; Lamounier, Maria Lúcia. 2014. "Land inequality in a coffee economy: São Paulo during the early twentieth century”. Working Paper n 2014-1. Department of Economics, FEA-USP, 1-33.

Cunha, Idaulo José. 1982. "Evolução econômico-industrial de Santa Catarina”. Florianópolis: FCC.

Cunha, Idaulo José. 1992. "O salto da indústria catarinense: um exemplo para o Brasil”. Florianópolis: Paralelo 27.

Ferenczi, Imre; Willcox, Walter F. 1929. "International migrations”. Vol. 1: Statistics. Nova York: NBER.

Ferreira, Luiz Mateus da Silva. 2019. "Terra, Trabalho e Indústria na Colônia de Imigrantes Dona Francisca (Joinville), Santa Catarina, 1850-1920”. Tese de Doutorado. São Paulo: FFLCH/USP.

Ficker, Carlos. 1965. "História de Joinville". $2^{\mathrm{a}}$ edição. Joinville: Imp. Ipiranga.

Furtado, Celso. 2005. "Formação econômica do Brasil". São Paulo: Cia Nacional.

Garavazo, Juliana. 2006. "Riqueza e Escravidão no Nordeste Paulista: Batatais, 1851-1887”. Dissertação de Mestrado. São Paulo: FFLCH/USP.

Hering, Maria Luiza Renaux. 1987. "Colonização e indústria no Vale do Itajaí: o modelo catarinense de desenvolvimento". Blumenau: Editora da FURB.

Hoffmann, Rodolfo. 1979. "Estimação da desigualdade dentro de estratos no cálculo do índice de Gini e da redundância". In: Pesquisa e Planejamento Econômico. Rio de Janeiro, 9(3), dez., 719-738.

Hoffmann, Rodolfo. 1998. "Distribuição de Renda: medidas de desigualdade e pobreza". São Paulo: Edusp.

Machado, Paulo Pinheiro. 2004. "Lideranças do Contestado: a formação e a atuação das chefias caboclas". Campinas: Unicamp.

Mamigonian, Armen. 1960. "Brusque: Estudo de geografia urbana e econômica". In: Álbum do Centenário de Brusque. Brusque: Edição da Sociedade Amigos de Brusque.

Mamigonian, Armen. 1965. "Estudos geográficos das indústrias de Blumenau”. In: Revista Brasileira de Geografia, v. 27, $\mathrm{n}^{\circ}$ 3. Julho-Setembro, 389-481.

Mamigonian, Armen. 1986. "Geografia das indústrias de Santa Catarina”. In: Atlas de Santa Catarina. Florianópolis: Geosul.

Marcondes, Renato Leite. 1998. “A arte de acumular na gestação da economia cafeeira: formas de enriquecimento no vale do Paraíba paulista durante o século XIX". Tese de Doutorado. São Paulo: FEA/USP.

Marcondes, Renato Leite. 2001. "A estrutura fundiária e cafeeira de dois municípios do oeste paulista: Campinas e Ribeirão Preto no início do século XX”. In: Revista de História, nº 165, jul./dez., 403-424.

Petrone, Maria Thereza S. 1982. "O imigrante e a pequena propriedade, 1824-1930”. São Paulo: Brasiliense.

Estud. Econ., São Paulo, vol.50 n.3, p.485-512, jul.-set. 2020 
Piazza, Walter F. 1975. “O escravo numa economia minifundiária”. Florianópolis: UDESC; São Paulo: Resenha Universitária.

Piazza, Walter F. 1976. "Introdução à história da propriedade rural em Santa Catarina”. In: A Propriedade Rural, Org. Eurípedes Simões de Paula. São Paulo: Coleção da Revista de História, Vol. II, 627-680.

Piazza, Walter F. 1994. “A colonização de Santa Catarina”. $3^{\circ}$ edição. Florianópolis: Lunardelli.

Piazza, Walter F. 1999. “A escravidão negra numa província periférica”. Florianópolis: Garapuvu.

Prado Jr., Caio. 1945. "Distribuição da propriedade fundiária rural no Estado de São Paulo". In. Boletim Geográfico, v.3, nº. 29, 692-700.

Prado Jr., Caio. 2006. "História econômica do Brasil”. São Paulo: Brasiliense.

Rodowicz-Oswiecimsky, Theodor. 1992. “A colônia Dona Francisca no sul do Brasil” [1853]. Florianópolis: EDUFSC, FCC; Joinville: FCJ.

Schneider, Adolfo Bernardo. 1983. "Povoamento, imigração e colonização: a fundação de Blumenau e Joinville". Joinville: edição do autor.

Serpa, Élio. 1999. “A Guerra do Contestado, 1912-1916”. Florianópolis: EDUFSC.

Seyferth, Giralda. 1999. “A colonização alemã no Vale do Itajaí-Mirim”. Porto Alegre: Movimento.

Tschudi, Johan Jakob v. 1867. "Reisen durch Südamerika”. Band. III. Leipzig: F. A. Brockhaus.

Waibel, Leo. 1958. "Capítulos de geografia tropical e do Brasil”. Rio de Janeiro: IBGE. 


\section{Apêndice}

Tabela Al - Número de habitantes e taxa de crescimento populacional na colônia Dona Francisca, 1851-1886

\begin{tabular}{|c|c|c|}
\hline Ano & Total de habitantes & $\begin{array}{c}\text { Taxa de crescimento } \\
\text { populacional }\end{array}$ \\
\hline 1851 & 394 & - \\
\hline 1852 & 687 & $74,4 \%$ \\
\hline 1853 & 757 & $10,2 \%$ \\
\hline 1854 & 1.194 & $57,7 \%$ \\
\hline 1855 & 901 & $-24,5 \%$ \\
\hline 1856 & 1.428 & $58,5 \%$ \\
\hline 1857 & 1.700 & $19,0 \%$ \\
\hline 1858 & 2.250 & $32,4 \%$ \\
\hline 1859 & 2.475 & $10,0 \%$ \\
\hline 1860 & 2.885 & $16,6 \%$ \\
\hline 1861 & 3.050 & $5,7 \%$ \\
\hline 1862 & 3.675 & $20,5 \%$ \\
\hline 1863 & 4.120 & $12,1 \%$ \\
\hline 1864 & 4.263 & $3,5 \%$ \\
\hline 1865 & 4.275 & $0,3 \%$ \\
\hline 1866 & 4.475 & $4,7 \%$ \\
\hline 1867 & 4.667 & $4,3 \%$ \\
\hline 1868 & 5.237 & $12,2 \%$ \\
\hline 1869 & 6.185 & $18,1 \%$ \\
\hline 1870 & 6.452 & $4,3 \%$ \\
\hline 1871 & 6.671 & $3,4 \%$ \\
\hline 1872 & 6.810 & $2,1 \%$ \\
\hline 1873 & 7.558 & $11,0 \%$ \\
\hline 1874 & 7.860 & $4,0 \%$ \\
\hline 1875 & 8.155 & $3,8 \%$ \\
\hline 1876 & 9.298 & $14,0 \%$ \\
\hline 1877 & 12.448 & $33,9 \%$ \\
\hline 1878 & 11.877 & $-4,6 \%$ \\
\hline 1879 & 16.967 & $42,9 \%$ \\
\hline 1880 & 18.229 & $7,4 \%$ \\
\hline 1881 & 19.455 & $6,7 \%$ \\
\hline 1882 & 19.825 & $1,9 \%$ \\
\hline 1883 & 23.800 & $20,1 \%$ \\
\hline 1884 & 24.100 & $1,3 \%$ \\
\hline 1885 & 25.000 & $3,7 \%$ \\
\hline 1886 & 26.000 & $4,0 \%$ \\
\hline
\end{tabular}

Fontes: Relatórios estatísticos da colônia, cx 1, prat. 41, Série Sociedade Colonizadora. BR SCAHJ CF 12; Relatórios da Direção da Sociedade Colonizadora de 1849 em Hamburgo, 1851-1892. Traduções Helena Remina Richlin. AHJ. 
Tabela A2 - Gini de concentração fundiária entre proprietários de terras no Brasil e Unidades da Federação, 1920

\begin{tabular}{|c|c|}
\hline Brasil/UFs & Gini \\
\hline Brasil & 0,835 \\
\hline Espírito Santo & 0,567 \\
\hline Pernambuco & 0,627 \\
\hline Ceará & 0,721 \\
\hline Rio de Janeiro & 0,724 \\
\hline Rio Grande do Norte & 0,724 \\
\hline Alagoas & 0,725 \\
\hline Minas Gerais & 0,726 \\
\hline Maranhão & 0,742 \\
\hline Paraíba & 0,747 \\
\hline Sergipe & 0,761 \\
\hline Mato Grosso & 0,761 \\
\hline São Paulo & 0,766 \\
\hline Santa Catarina & 0,766 \\
\hline Goiás & 0,784 \\
\hline Rio Grande do Sul & 0,800 \\
\hline Paraná & 0,811 \\
\hline Bahia & 0,811 \\
\hline Piauí & 0,821 \\
\hline Distrito Federal & 0,835 \\
\hline Pará & 0,877 \\
\hline Amazonas & 0,902 \\
\hline Território do Acre & 0,937 \\
\hline
\end{tabular}

Fonte: Calculado de Brasil, Recenseamento do Brazil de 1920. Agricultura. Vol. III, 1ª parte. 